\title{
A scary statistic
}

\section{The human population will soon reach seven billion. Scientists must detail demographic change and its interaction with the climate at a scale that enables policymakers to plan effectively.}

\begin{abstract}
By 31 October - Halloween or All Hallows' Eve - the world's population will have reached seven billion, according to United Nations (UN) demographers. That means that in just over ten years, we will have added more than one billion people to the human race, the same number gained over the entire nineteenth century. The world's population hasn't fallen since the Black Death of the fourteenth century, but never before has it risen so sharply - there are people alive today who will have witnessed a trebling of the planet's human population within their lifetimes. Although there is evidence that this trend will slow, it is far from abating: UN predictions indicate that by mid-century, the total number will have reached somewhere between 8 and 10.5 billion.
\end{abstract}

Although predicting population trends is always an uncertain business, this figure is informed by the fact that people are now living for longer, and that almost a quarter of those alive today are women of reproductive age. On the one hand, the success of our species represents hard-won triumphs in both science and policy that should be applauded. People who would have once died in childhood are now surviving to have children themselves. The eradication of diseases, such as smallpox, through medical advances has brought a better quality of life for many as well as a longer one. In India, the average lifespan has increased from 38 years in 1952 to 64 years today, and in China from 41 years to 73 years over the same period.

The topic of population growth can be a bit passé in sustainability circles, no doubt in part because of ill-conceived control measures to regulate childbirth. The consequences of an expanding human populace look severe, however, for a world with increasingly stressed energy and food supplies. Indeed, most of the extra two to three billion people born between now and 2050 will live in the cities and towns of low-income countries in Africa and Asia, where fertility rates continue to be high. As highlighted in a News Feature on page 331, what makes the UN figures especially worrisome is that the areas likely to experience most growth are also those likely to be affected by climate change and least able to cope with the extra demand on resources.
A breakdown of the figures makes real the scale of the problem for the regions most affected. At present, $13 \%$ of the world's population live in at-risk coastal areas, and $75 \%$ of those people are located in Asia. And although just over $50 \%$ of the world's inhabitants now live in urban areas, this number will rise to almost $69 \%$ by 2050. Some of the statistics are startling: in Beihai on the south coast of China, which predicted to be the world's fastest-growing city between now and 2020, population is expanding at a rate of $10.58 \%$, and in Niger, the average female still has more than seven children in a lifetime.

\section{The planet is already feeling the strain of its near seven billion human inhabitants, spelt out in lost species, rivers that have run dry and air that is thick with chemicals.}

One of more obvious impacts of population growth will be overcrowding in cities, particularly in poor cities, where malnutrition, dehydration, and disease are already rife. Globally, one billion people are now suffering from food shortages and water scarcity, a figure that could possibly treble within 40 years. Added to this will be the masses living in areas vulnerable to sea-level rise and storms, and those trying desperately to eek out a more comfortable existence. Yet, the planet is already feeling the strain of its near seven billion human inhabitants, spelt out in lost species, rivers that have run dry and air that is thick with chemicals. If those being born between now and 2050 continue on the development pathway of the present population, they will experience these impacts to an even greater extent. They may well also experience a lesser-appreciated outcome of the nexus of extreme climate and overcrowding: conflict. Increasingly, researchers are unearthing evidence of a link between civil unrest and higher temperatures, as highlighted in a News Feature on page 327. Most recently, a paper showed that $21 \%$ of 234 conflicts during the period 1950-2004 were probably instigated with the help of El Niño's hot, dry hand (Nature 476, 438-441; 2011). Much of the civil conflict that arises globally is also sparked by resource scarcity and access issues. As the climate warms and populations grow, regions that are hotspots for both are more likely to become conflict zones.

As with other hazards, forecasting these outcomes would make avoidance, or at least preparation, an option. As pointed out in the News Feature on page 331, however, amazingly little information is currently available on population at the scales needed to enable such adaptation efforts. Although we have a broad sense of where the focal points of population and climate change are, we simply don't know enough about how people live in these areas their age structure, income and exact location, for example - for policymakers to plan effectively. Demographers must make collecting and analysing this data a research priority, and make it available to those responsible for adaptation and risk assessment, as well as to the wider research community so that interdisciplinary collaborations on the population-climate nexus can evolve. Only then will it become apparent where funds for adaptation and education - especially of women - will be most effective, and where harder choices such as relocation may have to be considered. Here, social scientists will play a vital role in informing planners on issues such as the relationship between age structure, economic growth and social mobility in a resource-limited and overcrowded world.

In turn, policymakers must listen; on a planet that is likely to have nearly ten billion inhabitants by 2050, the suitability of pro-natalist population policies must be called into question. In some cases, immigration policies form part of the solution, but these will need to be matched with massive investment in education. Policymakers must face the consequences of ignoring information already available, for example, on the human and economic risks of unabated coastal development. We may well have reason to be scared at the thought of Earth's seven-billionth person being born by the end of October, but well informed and willing to act, we will be prepared. 